\title{
Numerical modelling of the high rock stress challenges at Rana mine, Norway
}

\author{
N.Q. Trinh ${ }^{1}$, T.E. Larsen ${ }^{1}$, S. Molund ${ }^{2}$, B. Nøst ${ }^{2}$, and A. Kuhn ${ }^{2}$ \\ 1SINTEF AS, Infrastructure, Rock and Soil Mechanics, Norway \\ ${ }^{2}$ Rana Gruber AS, Norway
}

\begin{abstract}
Rana Gruber AS is an iron mining company in the north of Norway, and operates the Kvannevann mine $30 \mathrm{~km}$ east of Mo i Rana. The Kvannevann mine is located in a foliated gneiss host rock, with an ore body about $70 \mathrm{~m}$ wide and more than $300 \mathrm{~m}$ deep. During the history of the mine, it has been in operation for many years using an open-pit mining method, which was later it converted to sublevel-stoping. After thorough planning and preparation, the sub-level cave mining method was put in operation in 2012. Experience from past mining activities and in the preparation of infrastructure for the new mining method indicates that the mine is located in a hard, brittle rock mass with high horizontal stresses. Stress measurements have been made from time to time. The measurement results indicate a major principal stress of approximately $20 \mathrm{MPa}$ perpendicular to the strike of the ore, and a minor principal stress of approximately $10 \mathrm{MPa}$ parallel to the strike of the ore, which is 10-15 times higher than the theoretical vertical stress caused by gravity at the measured location. This paper presents some challenges related to high stress during development and operation of the mine. The paper also presents a comprehensive rock mechanics program, applying a combination of stress measurements, numerical modelling, and monitoring, to deal with the situation.
\end{abstract}

\section{INTRODUCTION}

The Kvannevann mine is one of several iron ore mines operated and owned by Rana Gruber AS in the Dunderland valley, east of the city of Mo i Rana, Nordland county, Norway. The Kvannevann mine is the only underground mine in the region, and is located in the northern part of Norway, approximately $50 \mathrm{~km}$ south of the Arctic Circle. Today Rana Gruber AS combines underground and open-pit methods for mining and the concentrated iron ore is used for multiple purposes. The majority of the concentrates are used for iron and steel production, while smaller quantities are tailored for special applications. The main steps of the process are: mining, crushing and storage of crude ore at the Ørtfjell deposit, railway transport to the dressing plant in Mo i Rana, a distance of approximately $35 \mathrm{~km}$, mineral dressing and concentration, storage of concentrates and supply to customers via the company's own shipping terminal.

The mine has the largest deposit of iron ore in the area and has been known since before 1799. Various persons and companies tried to exploit the iron ore in the 19th century. The Swedish industrialist Pehrsson in the late 1800s obtained land needed for mining and factory sites, including areas expropriated for the construction of a railway reaching a suitable harbour location at Gullsmedvik, Mo i Rana. In 1901 all of this was bought by The Edison Ore Milling Syndicate. This company was established by the American inventor Thomas Alva Edison in order to exploit patents he held on magnetic separation of iron ore. Mining operations after four years of construction began in 1906 by English Dunderland Iron Ore Company (DIOC). DIOC completed its business in at the mine in 1939, when Germany went to war with England in September 1939. After WW2, the ownership of the mine changed from state-owned, to employee-owned, to private ownership. 
From February 22, 2008, 2/3 of the shares in Rana Gruber were acquired by the company Leonhard Nilsen \& Sons Company (according to Rana Gruber AS, 2019).

The mining activity at the Rana mine can be summarised as follows:

- 1906-1997: The mine operated with several open-pit mines;

- 1997-2000: Preparation for the new underground operation at Kvannevann, and it continued with open-pit mining in the area.

- 2000-2008: Start-up of the new underground mine at Kvannevann with the sub-level open stope mining method. Continuing with open-pit mining in the neighbouring areas;

- 2008-2012: Rana Gruber becomes a LNS-company. The company carried out plan and preparation works for new mining method for the Kvannevann mine - Sub-level caving.

- 2012: New mining method sub-level caving in operation.

\section{Sub-level open-stope mining}

During the sub-level open-stope mining (2000-2012), the method has been used over a total length of $1,200 \mathrm{~m}$ of stopes in the Kvannevann ore body. The main and first production level was established at $250 \mathrm{~m}$ above sea level. A total of 16 stopes, on average $60 \mathrm{~m}$ long, $30 \mathrm{~m}$ wide and $100 \mathrm{~m}$ high, were aligned along the ore body. These were separated by a number of 15 to $30 \mathrm{~m}$ thick vertical pillars. The bottom of the former open pit, at an average altitude of $400 \mathrm{~m}$ above sea level, was used for the roof for the Kvannevann underground mine. The crown pillar from the bottom of the open-pit to the top level of the sub-level open stope is on average $30 \mathrm{~m}$ thick. Location and general mine layout of the sub-level open stope is as presented in Figure 1 (Sand, 2010 and Sand and Trinh, 2011).

Production drilling was carried out from production drifts at a level of $320 \mathrm{~m}$. A standard $360^{\circ}$ fan was drilled every $3 \mathrm{~m}$ with hole lengths chosen to encompass the iron ore. Additional production drilling was done from level $250 \mathrm{~m}$ upwards to create a funnel-shaped design for the lower part of the stope.

\section{Sub-level caving}

In 2008, Rana Gruber was taken over by Leonard Nilsen \& Sønner AS (LNS), a company with international reputation in tunnelling, excavation of rock and construction. The new owners immediately focused on the investigation of alternative mining method, in order to raise production and lower mining costs with the aim to manifest a long-term mining for iron ore in the area. The investigation resulted in the decision to change from open stope to sub-level caving: Project sub-level caving (See Figure 2).

In this sub-level caving project, it was planned to develop 4 mining levels, which are $221 \mathrm{~m}, 187 \mathrm{~m}, 155$ $\mathrm{m}$, and $123 \mathrm{~m}$ above sea level. Vertical distance between the levels is approximately $30 \mathrm{~m}$. The distance between production drift is $22 \mathrm{~m}$, and thickness of each fans is approximately $3 \mathrm{~m}$. Ore thicknesses within the sub-level caving project area varies from $30 \mathrm{~m}$ to more than $100 \mathrm{~m}$. Thus, the extractable ore in the Kvannevann Mine was estimated at 44.8 million tonnes, based on sub-level caving between level $221 \mathrm{~m}$ to $123 \mathrm{~m}$ above sea level, Sand (2010).

The planning team of the project identified risks for the project in order to carry out the necessary analyses. Based on the risk identification, the project group concentrated on the main issues as summarized, Sand (2010):
a) The geometry of the ore body
b) Pillar production
c) Large-scale stability
d) A satisfactory caving of the hanging wall and footwall
e) Local stability of the hanging wall and the footwall
f) Location of the field tunnels, including transport tunnels, shafts, and crushing hall
g) Rock reinforcement
h) Extraction values and cut-off 
i) Consequence and risk assessment.

This article presents high stress conditions of the mine and a method to deal with such condition by using comprehensive 3D numerical modelling together with a monitoring system to verify the result and follow-up the situation.

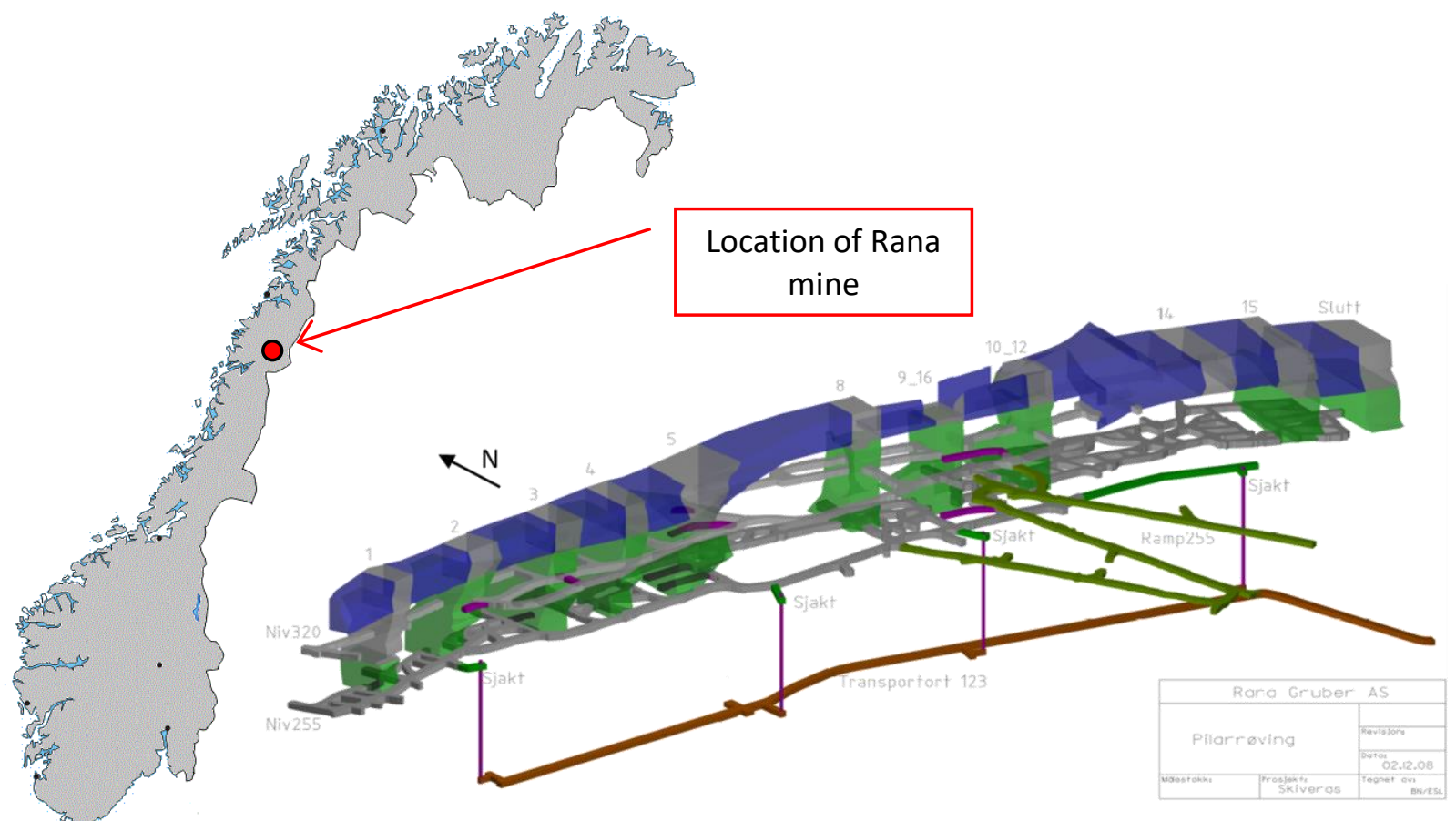

Figure 1. Location and 3-D picture of level 250m. Crown pillars coloured in blue and grey, vertical pillars in green, Sand and Trinh (2011).

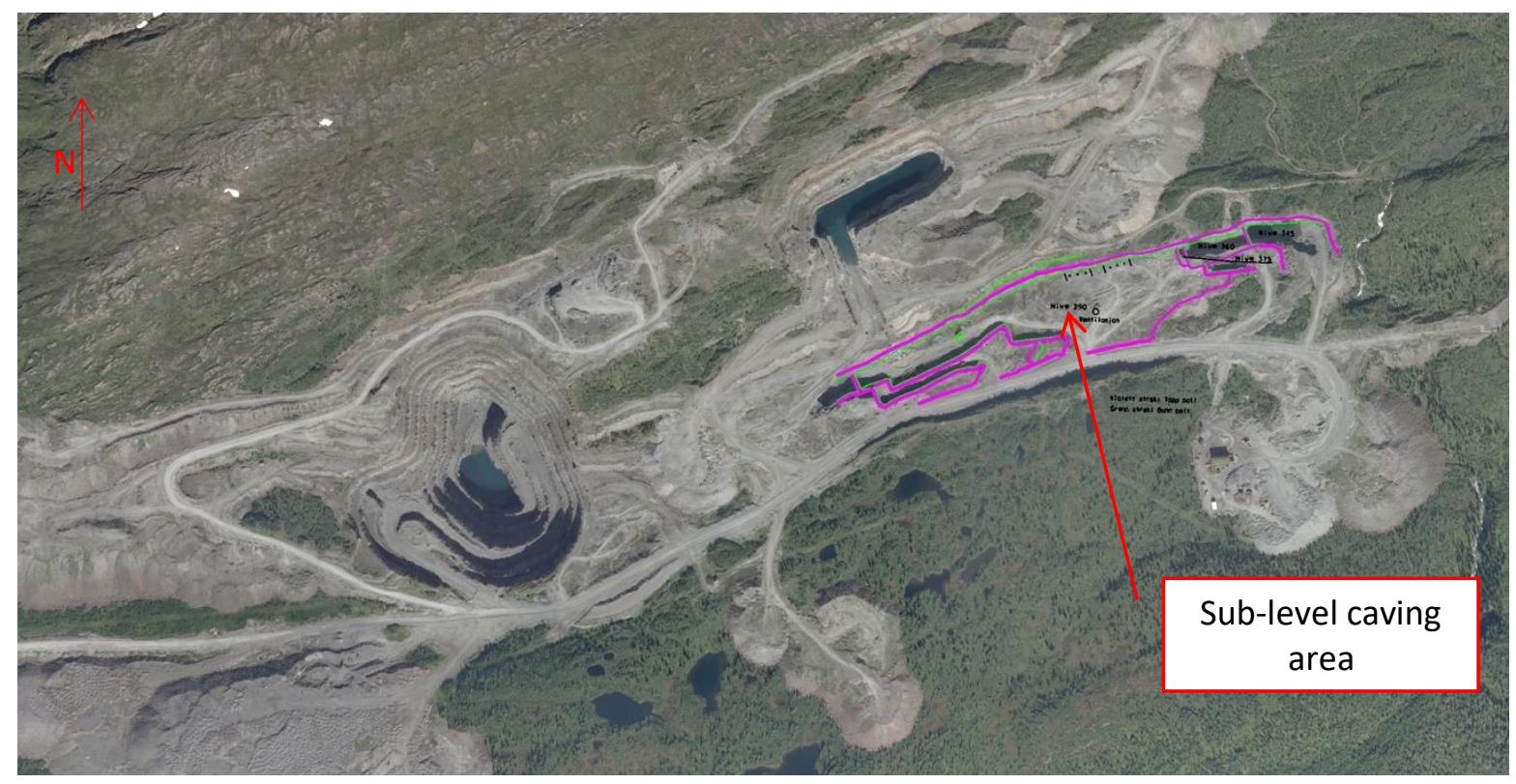

Figure 2. Location of sublevel caving area in relation to the existing open-pit mine 


\section{Geology and rock mechanics conditions at Rana mine}

As described in Sand (2010), the Ørtfjell iron ore deposit is embedded in meta-sediments and volcanic rock, probably from the Proterozoic age, some 1.2 billion years old. The geological rock unit is made up of mica schists, calcareous garnet-mica schists, limestones and small layers of amphibolites and quartzites. The rocks show a distinct foliation due to a severe tectonic overprint represented by at least three folding cycles. The iron ore is in direct contact of either limestones or mica schists. As the result of isoclinals folding, the iron ore deposit is a multiple of its original thickness. The ore is banded due to varying iron oxide concentrations. The flanks of the bowl-like fold structure dip steeply towards north and south respectively. The bottom of the fold is estimated to be approx. $700 \mathrm{~m}$ below sea level. The Kvannevann mine is situated on the southern flank of the fold structure. The currently mined ore has an extension of $1200 \mathrm{~m}$ with thicknesses varying from $30 \mathrm{~m}$ to more than $100 \mathrm{~m}$. The ore body has been proven to continue from surface at an average of $450 \mathrm{~m}$ above sea level to $10 \mathrm{~m}$ below sea level by diamond drilling and exploration tunnelling. The total Fe-content of the ore varies between $27 \%-35$ $\%$, averaging $33 \%$.

During previous mining activity (sub-level open stope) and early preparation of the infrastructure for the sub-level caving project, the rock mass showed many indications of a high stress condition.

The ramp from the surface down to $250 \mathrm{~m}$ above sea level), was extended down to $123 \mathrm{~m}$ above sea level, where a new crusher was planned. Incidents of rock bursts were experienced along the ramp. In some locations, where rock reinforcement was not sufficient, rock popped out of the wall, bringing with it the fibre-reinforced shotcrete. Large rock blocks falling down from the roof caused hazardous working conditions inside the tunnel. Rock bursts were also experienced at the excavation face, necessitating shotcreting. Most of the popped rock blocks had a typical lensed shape, which indicate high in situ rock stress. The problem occurred not only in the walls and roof, but was also observed in the floor. In the workshop at $250 \mathrm{~m}$ above sea level, the concrete floor heaved about $20 \mathrm{~cm}$ over time, resulting in many visible cracks. All of these observations convincingly demonstrated the high horizontal stresses in the mine.

Instabilities in the tunnel indicated that displacement before failure was rather small, almost unrecognisable from normal visual observation. The rock blocks were spalling without noticeable displacement in advance. The occurrence time varied from a few hours to days after excavation. From these observations, it could be argued that the rock failure is likely due to brittle rock, and that there is almost no or only a very short time the rock mass undergoes plastic deformation before failing completely. This is a typical behaviour of hard rocks under a high stress condition. Over the years, laboratory tests for mechanical properties such as Young modulus, Poisson ratio, uniaxial compressive strength, and unit weight were carried out and presented in Table I. To investigate the stress problems, in situ rock stress measurements were also performed from time to time, as shown in Figure 3.

Figure 3 provides information for estimating in situ stresses for the mine. It is noted that not all stress measurements in the figure are valid for estimating the in situ stress for the mine:

- All the 2D measurements were performed to identify the induced stress level surrounding pillar, shaft, and drift. Therefore, results from 2D measurements were not included when evaluating the in-situ stress situation in the area;

- Exact locations of the 3D stress measurements done in 1977 and 1979 are not easy to track down today with a high level of accuracy;

- The result of 3D stress measurement at level 123 done in 2017 seems not to be the in-situ condition, as it appears to be affected by large mining volume in the upper mining levels; and

- Therefore, the in-situ stress situation of the mine was estimated based on 3D measurement in the ramp, level 184. The measurement was carried out in 2008.

As can be seen in Figure 3, various options were used to assess the in situ stress situation based on stress measurement in the ramp, level 184. After due considerations and several numerical model attempts, 
the in-situ stress situation at Rana mine was found to likely be as follows:

- $\sigma 1=23 \pm 5 \mathrm{MPa}$ at level 184 and slightly varied with depth. Oriented almost north-south;

- $\sigma 2=18 \pm 5 \mathrm{MPa}$ at level 184 and slightly varied with depth. Oriented almost east-west;

- $\mathrm{o3}=\mathrm{MPa}-$ Vertical, gravity.

Table I. Laboratory tests carried out at Rana mine

\begin{tabular}{|ccccc|}
\hline Rock type & E-modul GPa & Poissons ratio & $\begin{array}{c}\text { UCS } \\
\mathrm{MPa}\end{array}$ & Unit weight kg/m3 \\
\hline Dunderland schist & 22.3 & 0.24 & 83.5 & 2827 \\
Lime marble & 52 & 0.17 & 75 & 2790 \\
Mica schist & 22.8 & 0.22 & 78.1 & 3052 \\
Limestone & 47.5 & 0.17 & 89.05 & - \\
Ore & 25.4 & 0.26 & 68.85 & 3587 \\
Schist/ore & 28.9 & 0.21 & 94.8 & 2909 \\
Hematite & 31.2 & 0.295 & 98.5 & 3490 \\
\hline
\end{tabular}

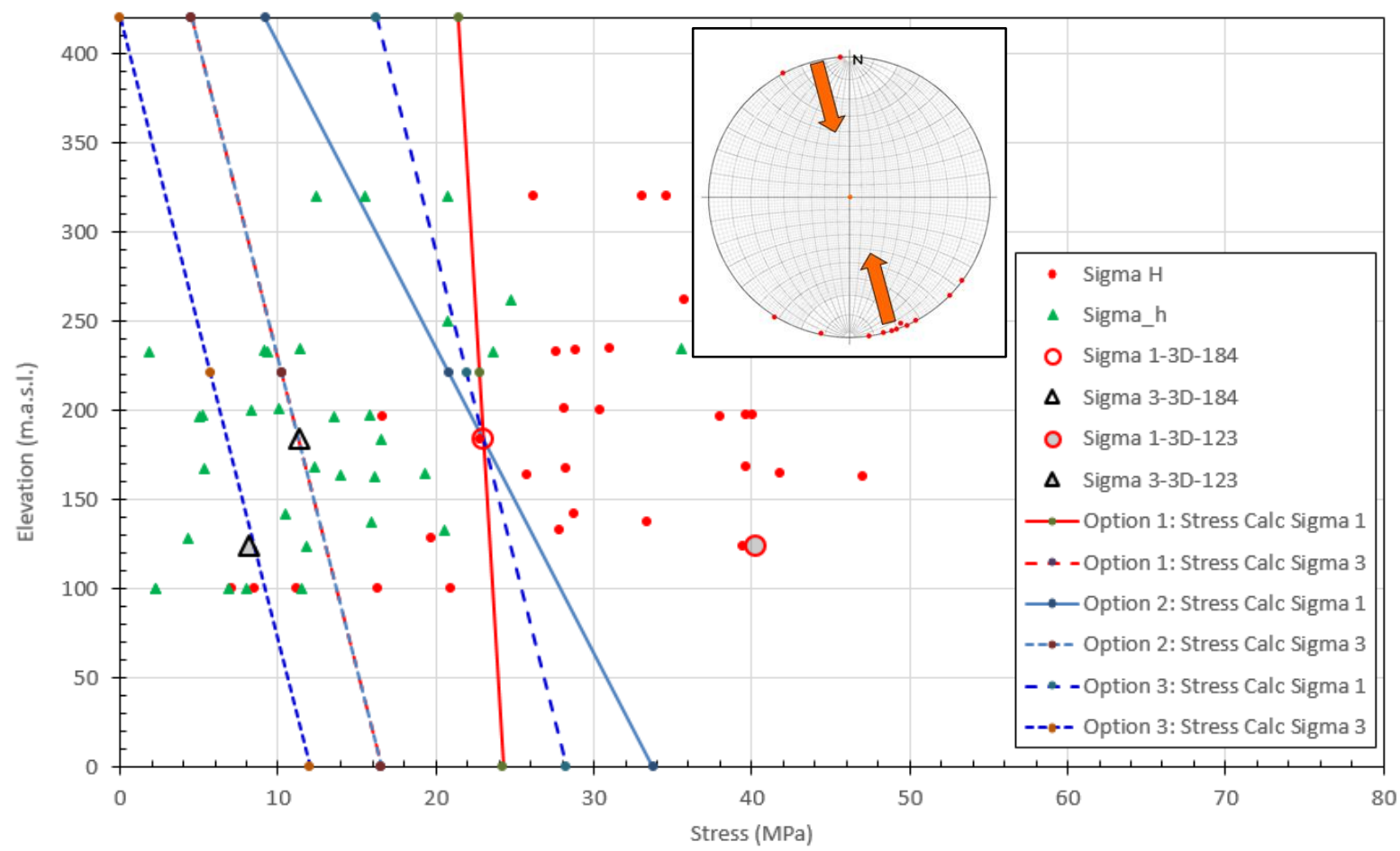

Figure 3. Results of stress measurement and the orientation of in-situ rock stress (for major principal stress sigma 1 in the smaller figure)

\section{NUMERICAL MODEL AND MONITORING}

\section{Numerical analyses for rock mechanical evaluations}

In connection with the sublevel caving project, many numerical analyses were carried out by stiftelsen for industriell og teknisk forskning (SINTEF) to study the design and layout of the mine, which are:

- Stability and rock support for the crusher hall, Trinh et al (2010);

- Numerical models for the hangingwall displacement, Sand and Trinh (2011);

- Stability study for the footwall, Trinh and Sand (2011);

- Simplified numerical analyses for evaluating different mining layouts;

- A detailed 3D numerical model was built for simulation of the mining operation for sub-level caving mine in Rana mine. 
This article focuses on the detailed 3D model together with the implementation of a monitoring program to deal with the known high stress condition at this mine.

The model was built in 2017, at the time when the sub-level caving mine had been in operation for 5 years. At that stage, level 221 was completed, and level 187 was almost completed. Various aspects of the mine were included in the model, such as infrastructure, four mining levels, caving fronts, an apparent pillar, and a hard rock area. The aim of the model was to:

- Study the stress situation caused by the mining development up that time;

- Investigate the stability condition of the mine in future mining steps, based on model result and practical experience in the mine.

Detailed configuration of the model is presented in Figure 4.

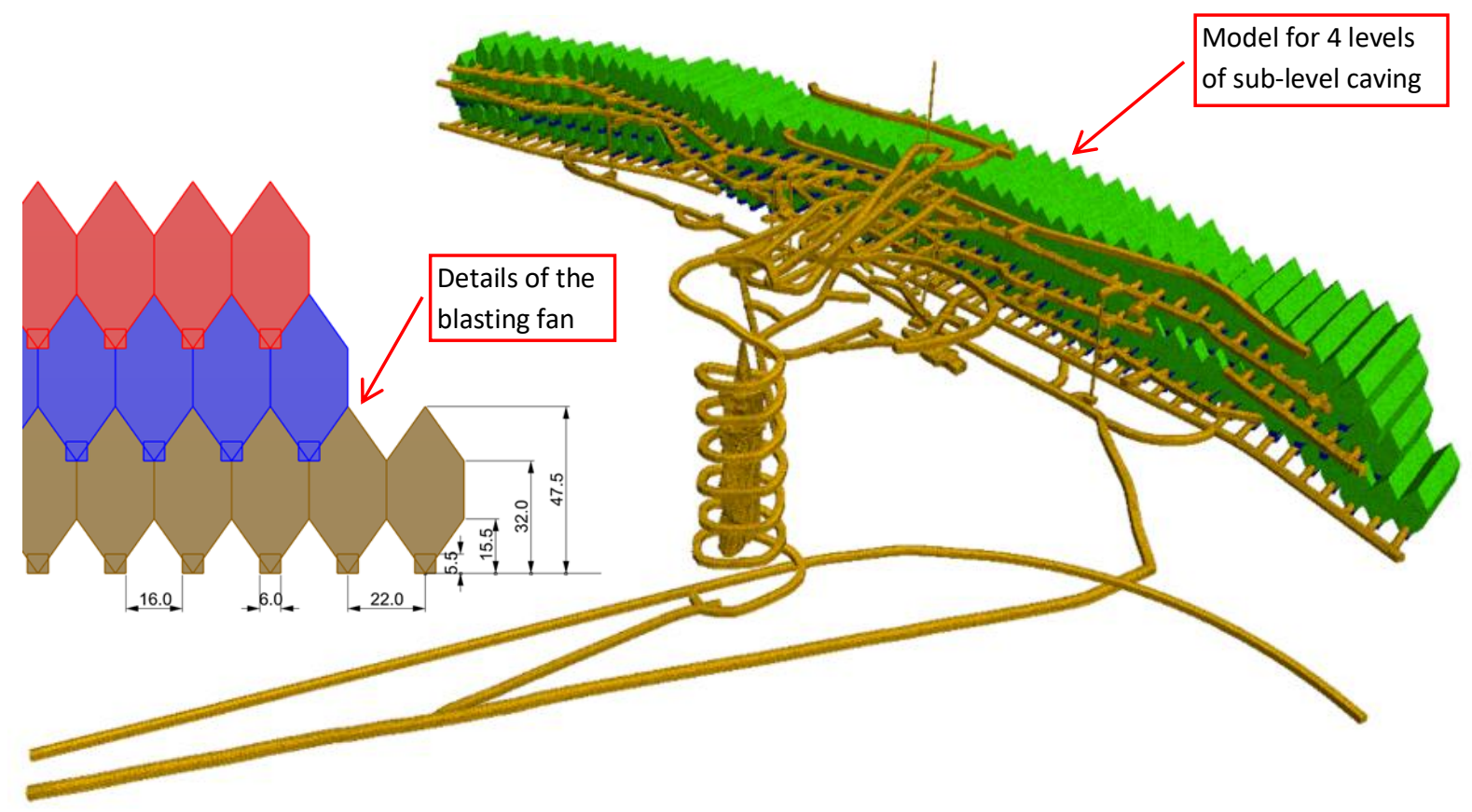

Figure 4. Detailed model for 4 levels of the sub-level caving project and details of the blasting fans in each mining level.

The purpose of the numerical modelling in this study was to simulate the entire mining development from start of sub-level caving up to 2017. Furthermore, two critical mining steps in the future mining development were also simulated to investigate the resultant rock mechanics situation. The mining progress simulated in the model was as follow:

- Mining from the surface to level 250 is simulated in one step;

- Level 221: all mining before 31/5/2013 is simulated in one step. After this step, there are 11 simulation steps;

- Level 187: there are 36 simulation steps;

- Level 153: there are 9 simulation steps +1 simulation for testing critical mining step; and

- Level 123: there is 1 simulation step for testing a critical mining step.

To prepare the model, the monthly location of caving fronts from May 2013 to January 2017 was collected and implemented in the model. An example of the caving fronts and the numerical model is shown in Figure 5. 


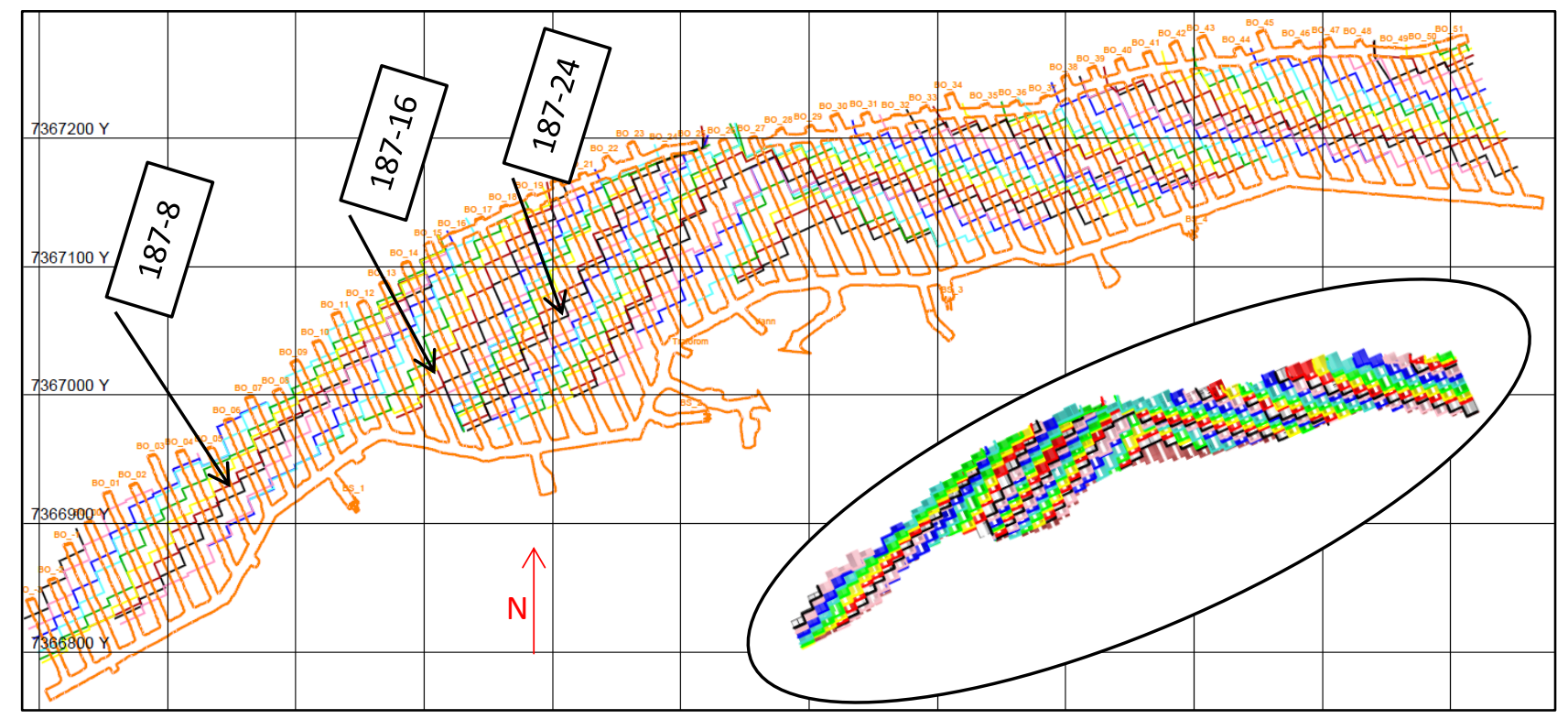

Figure 5. Collected caving fronts and the correspondent numerical model

The mining layout at Rana mine implies that sub-level mining for each level will start at two outer ends (East and west ends) and progress towards the centre. The caving fronts are angled $25^{\circ}$ to the longitudinal axis of the mine. With this layout, the contact zone between the ore body and hanging wall will be gradually reduced with mining progress. Thus, stress concentration at the central part of the mine will increase. From a certain mining step, the stress concentration starts to reach a level that may cause a failure situation in the production drifts. Mining steps with such high stress are so-called critical mining steps.

These critical mining steps were studied in earlier numerical studies, using simplified 3D numerical model in 2016. By using the detailed 3D model described here, the critical mining step can be studied in much more detail.

\section{Critical mining at Level 221}

From the previous simplified model (which is not presented in this paper), it is found that critical mining steps start from the mining step 221-7. The mining step 221-7 was reached on approximately $29 / 11 / 2013$. The mining progress approached the mine centre. In the central area, at this mining step, there were 3 drilling drifts, which were not separated from the hangingwall. Thus, the contact length between ore and hanging wall was approximately $60 \mathrm{~m}$ to $70 \mathrm{~m}$. The mining progress and result of sigma 1 at this mining step is presented in Figure 6.

Numerical modelling result of the stress situation at this mining step is also presented in vertical section in Figures 7 - at the central part of the mine. Location of this section is as shown as section A-A-221 in the plan view of Level 221. As shown in Figure 7, the stress (major principal stress - sigma 1) concentration locally in the corner between ore and hanging wall and footwall may reach $100 \mathrm{MPa}$ according to the numerical model - this very high value may be local and due to sharp corner between the ore and the rock walls. Sigma 1 in major part of the rock body above the drill drifts is more than 35 $\mathrm{MPa}$. The reason to choose contour line of sigma $1=35 \mathrm{MPa}$ for plotting will be discussed in the next section. 


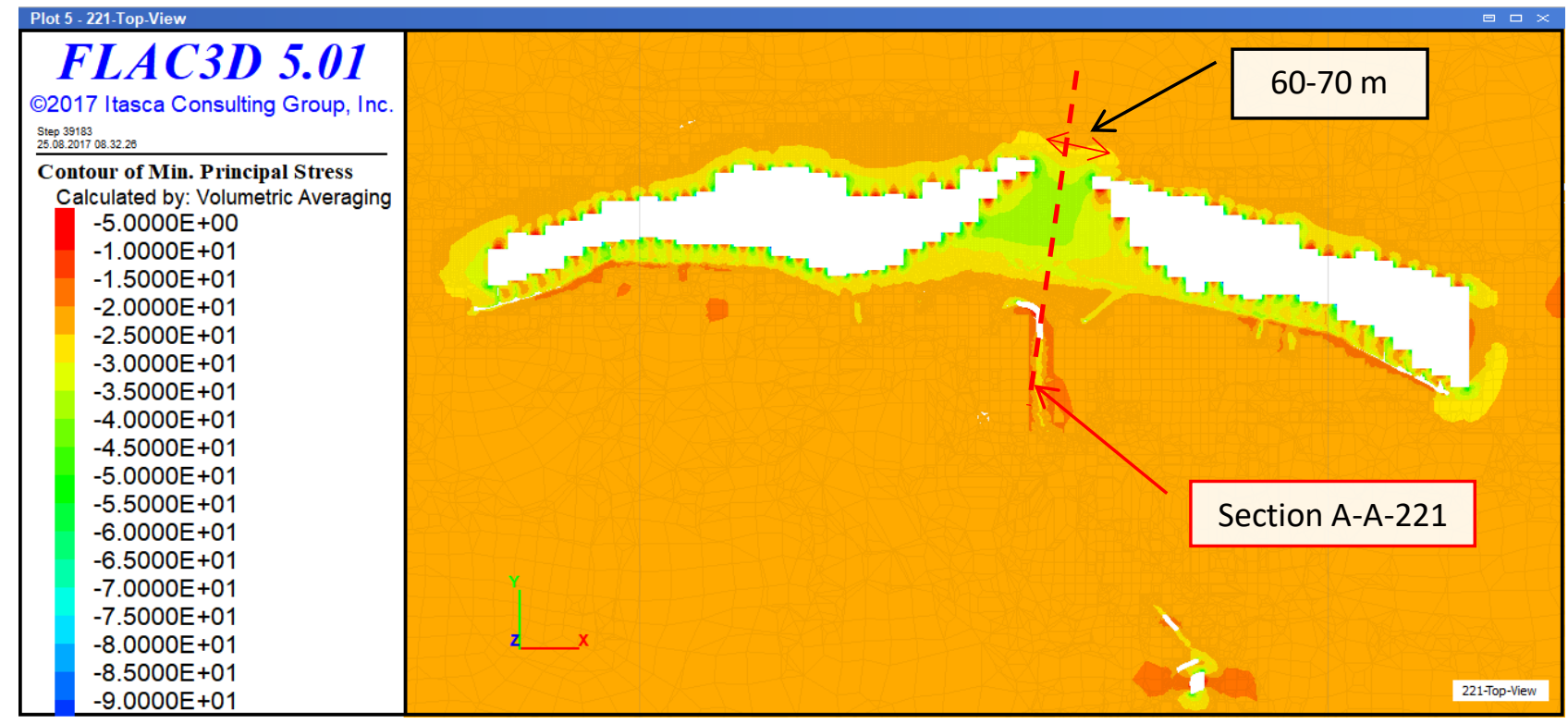

Figure 6. Major principal stress - Horizontal-section at elevation 235

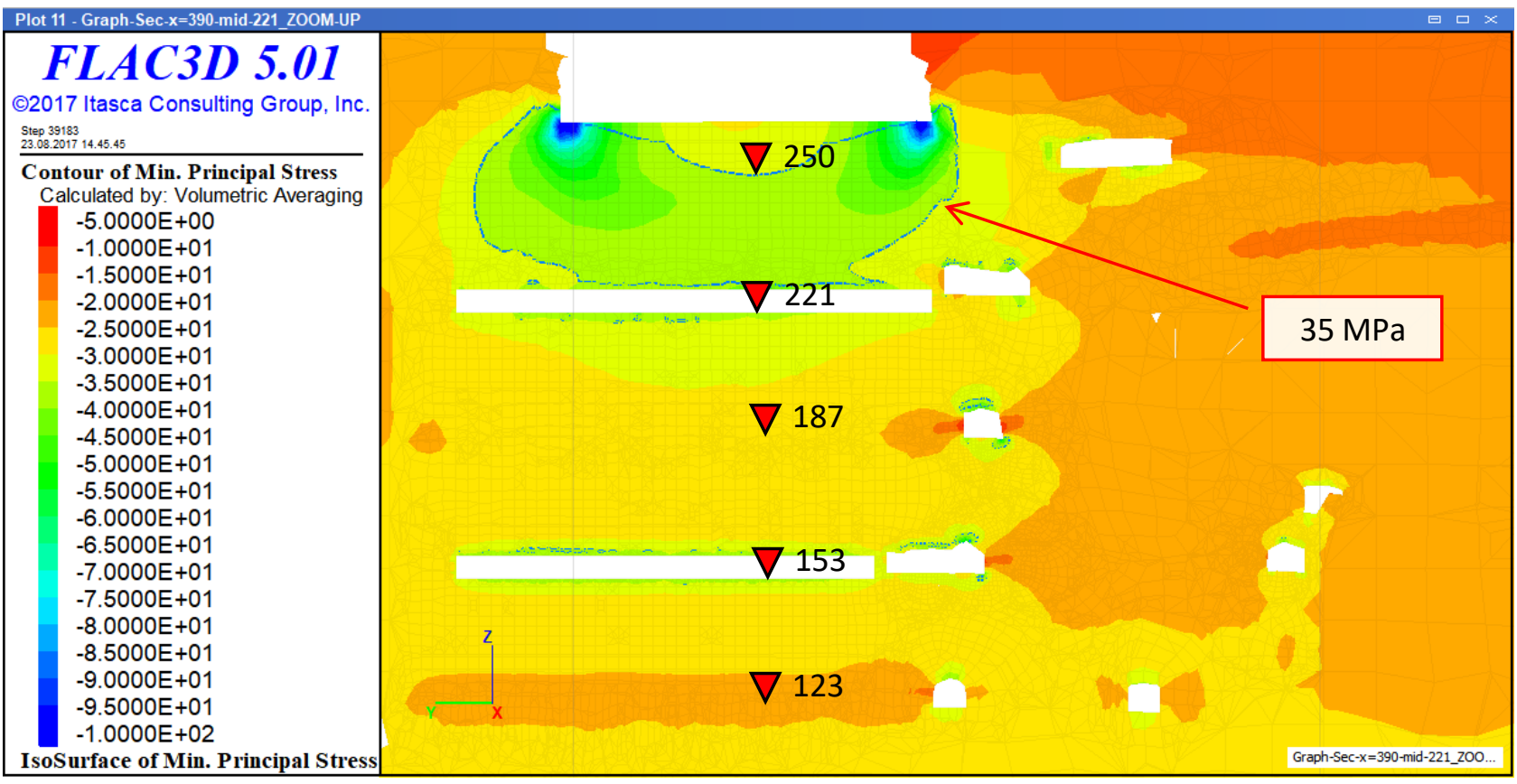

Figure 7. Major principal stress - Vertical-section at middle of the mine (section A-A-221)

\section{Critical mining at Level 187}

From the previous simplified model (which is not presented in this paper), it was found that critical mining steps started from the mining step 187-24. The mining step 187-24 was on approximately $28 / 12 / 2015$. The layout of this mining step is as shown in Figure 8 . The contact length between the ore and hanging wall in this mining step in level 187 is about $100 \mathrm{~m}$. The mining progress and model result of sigma 1 for this mining step is presented in Figure 8. The result of sigma 1 in a vertical section are as presented in Figure 10. 
As can be seen in Figure 10, the rock mass above drilling drifts at level 187 is subject to a sigma 1 of larger than $35 \mathrm{MPa}$, and differential stress is larger than $30 \mathrm{MPa}$. The stress concentration in the corner reaches more than $100 \mathrm{MPa}$ - this very high value may be local and due to the sharp corner between the ore and the rock walls. Some comments were made for the numerical model result for this critical mining step:

- The contour line of sigma $1=35 \mathrm{MPa}$ and differential stress $=30 \mathrm{MPa}$ appears in the infrastructure and most part of the rock mass in and above the drilling drifts. Locations of the area with these stress values coincide with the observed rock failure as shown in Figure 9;

- Especially as shown and noted in Figure 11, the contour line of sigma $1=35 \mathrm{MPa}$ (and the same location for the differential stress $=30 \mathrm{MPa}$ ) appears in the upper and lower corner of the infrastructure. This coincides well with the observation of the rock and shotcrete fracture as shown in the same figure; and

- The selected value of sigma 1 ( $35 \mathrm{MPa}$ ) is almost $50 \%$ of the UCS of the host rock and ore body (84 MPa and $75 \mathrm{MPa}$ respectively). Experience shows that in a low confinement situation, this could cause rock stability problem. In Q-system for example: in the table describing stress reduction factor - SRF, one may expect instability as soon as the ratio of uniaxial compressive strength of intact rock over sigma 1 is less than 5 , and an expectation of spalling or rock burst after a few minutes in massive rock when this ratio is from 3 to 2 .

Based on discussed arguments above, it would be reasonable to use sigma $1=35 \mathrm{MPa}$ and differential $=30 \mathrm{MPa}$ as an indicator for instability when analysing this 3D model results.

The model and the indicator were used for studying the critical mining steps for lower mining levels (levels 153 and 123). The model results forecast that it will be more critical in the lower levels.

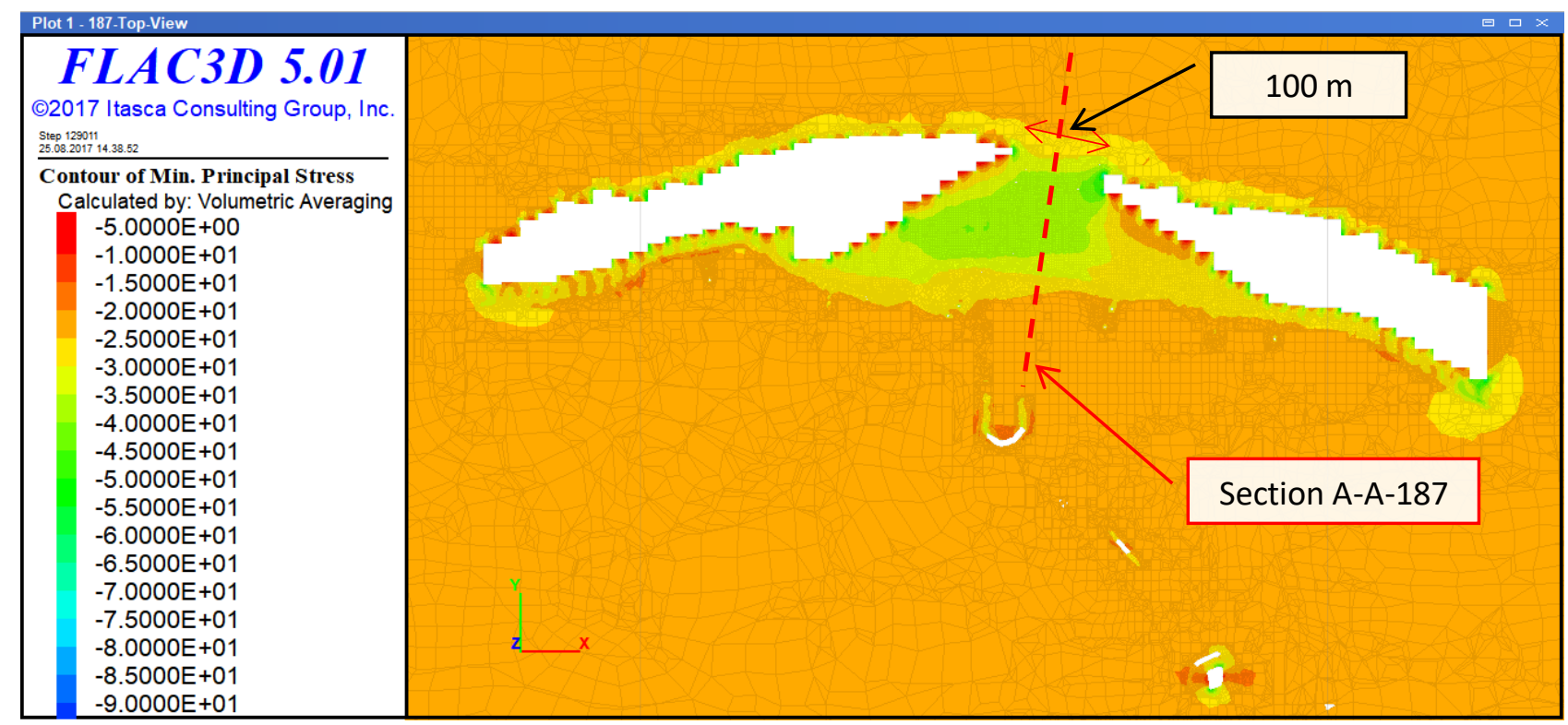

Figure 8. Major principal stress - Horizontal-section at elevation 205 

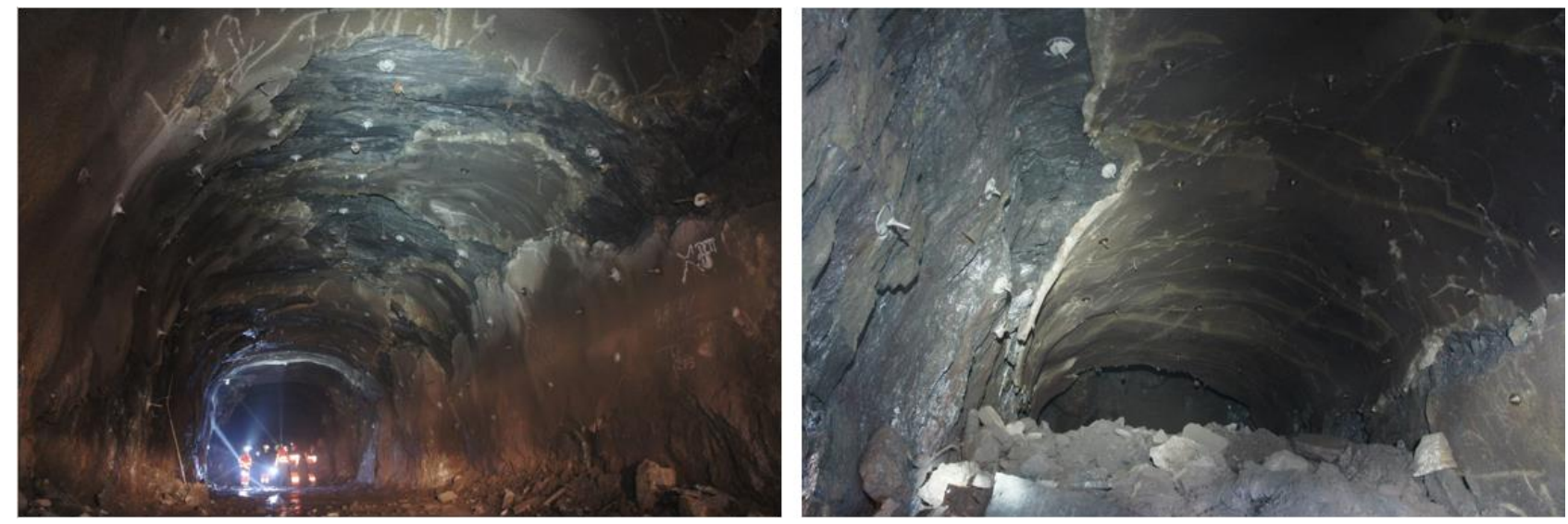

Figure 9. Observation in the drilling drifts in level 187 during critical mining steps (observed in drilling drift 27 - level 187 on 19/9/2016)

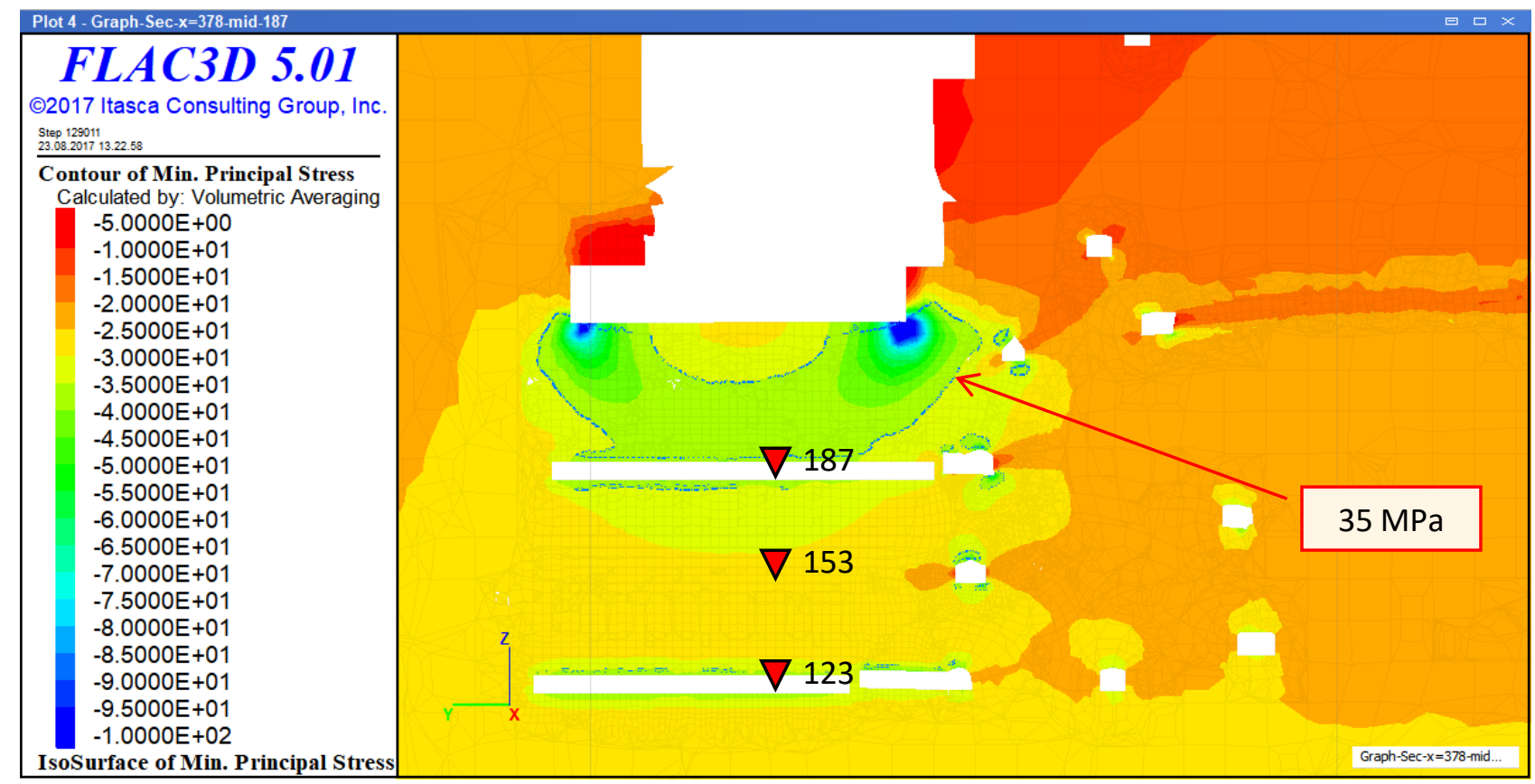

Figure 10. Major principal stress - Vertical-section at middle of the mine (section A-A-187) 


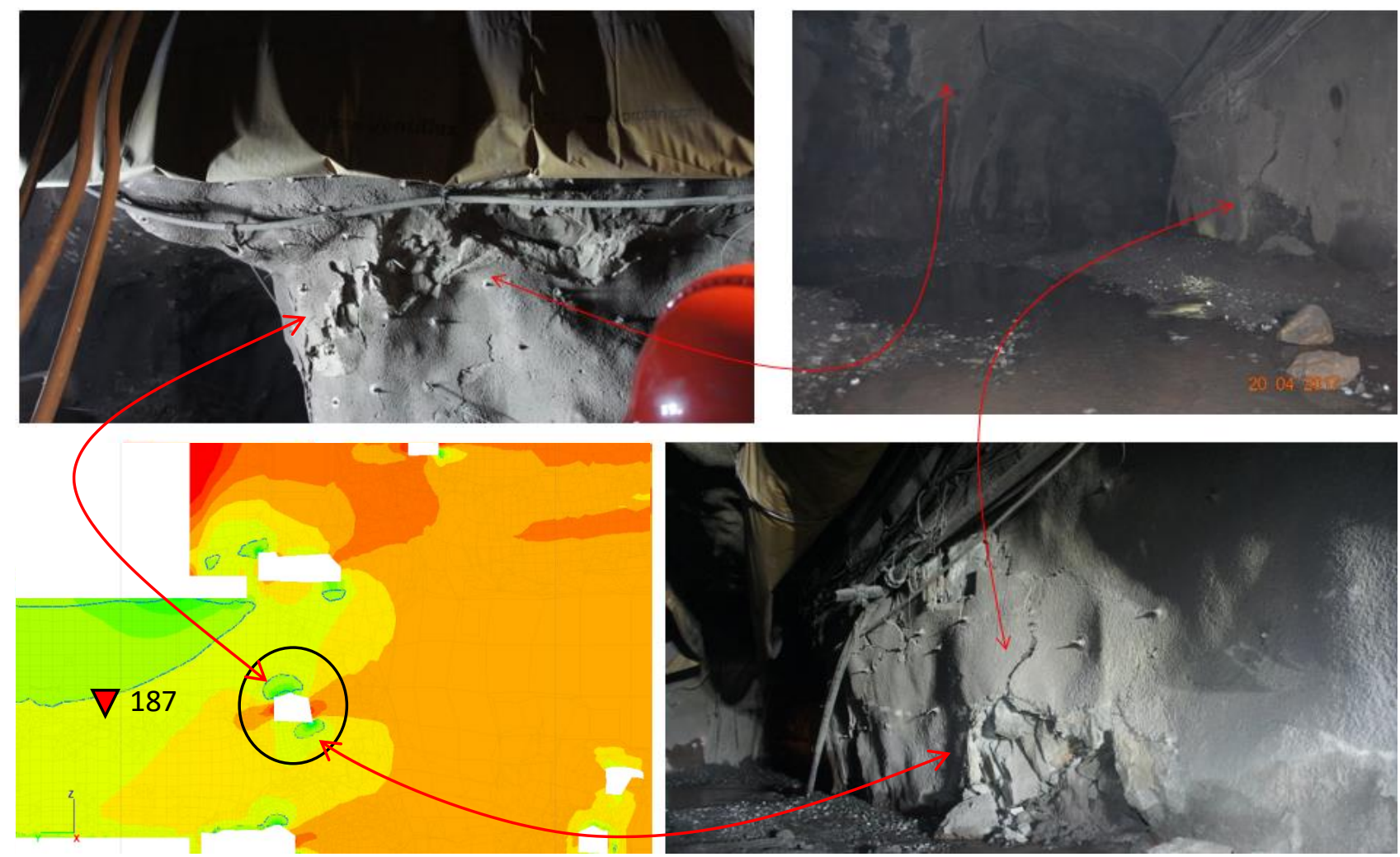

Figure 11. Observation in the infrastructure in level 187 during critical mining steps (observed along the field drift between drilling drift 27 to 20 - level 187 on 19/9/2016)

\section{Monitoring programme}

During planning and operation of the sub-level caving mine, a comprehensive monitoring program was established. The monitoring program to date consists of:

- Sixteen long-term-door-stoppers (LTDM) were installed at critical locations to monitor the stress development in the rock mass during mining progress. The development and component of the LTDM was presented in Trinh et al (2016); and

- Two extensometers were installed to monitor the displacement at the footwall of the mine;

The LTDMs and extensometers are located at different mining levels and along the infrastructure. Two of the LTDMs installed in Level 155 were installed closer toward hangingwall. The purpose of installing these two LTDM was that they will monitor the stress development during mining activity in this level to identify the critical stress level. Once the critical stress level is reached, the ore will be separated from the hangingwall to avoid stress concentration in the drilling drifts and improve safety condition for working in the drift and reducing the cost for rock support during critical mining steps.

Data from the monitoring system was collected and compared with the results of the numerical model to calibrate and improve the numerical model. Initial results of this comparison and recommendations for possible improvements will be presented in the conclusions below.

\section{CONCLUDING REMARKS}

The detailed 3D modelling was used to successfully study the critical mining steps in mining levels 221 and 187. The model results are able to reflect a high stress concentration at different part of the mine at different mining steps. The model results are useful when evaluating stress conditions during critical mining steps for the completed and future mining levels.

Comparing the model with actual measured data from LTDMs and observations, it becomes clear that 
the model still needs some improvements. Despite the comprehensive and thorough development of the 3D model, the model results still have some limitations in reflecting the logged data from LTDMs.

After comparison work, some comments are useful:

- When comparing the model results with monitoring data: In most of the LTDMs locations, the stress in the numerical model and LTDMs is comparable in the first part of the recorded data;

- Most of the model results do not show the tendency of stress increase as recorded in the LTDMs. Typical comparison between model results and monitoring data can be seen in Figure 12. The mechanism (that causes the increment of actual stress that the model failed to replicate) is not known. A possible reason may be that within the caved volume, there may be large blocks that act as pillars to transfer more stress from the hangingwall to the footwall. Randomly putting some "pillars" to act as the large rock blocks and transfer more stress from hangingwall to footwall may bring the model results closer to the logged data from LTDMs;

- In the central part of the mine (where the LTDMs L2, L8B, and T2 are located), the recorded stress seems higher than the stress result from the model. The "apparent pillar" and hard rock area does not have a positive effect in the numerical model as one may expect. Additional random pillars putting in the model and improving the properties of quartz-keratophyre may improve the modelling results;

- The hard rock area in the centre: The UCS of the quartz-keratophyre is about $100 \mathrm{MPa}$. This is higher than the UCS of host rocks and ore ( 84 and $75 \mathrm{MPa}$ respectively). However, the Young's modulus of $20.7 \mathrm{GPa}$ is lower than the Young modulus of the host rock and ore (26 GPa). In this numerical model, only elastic properties of the material were used (Young's modulus and Poisson ratio), the UCS was not used. Therefore, the harder rock became actually softer in this numerical model. A new set of simulations could be carried out with artificially higher rock mass quality of the quartz-keratophyre, so that the rock mass deformation modulus of the quartz-keratophyre becomes higher. This modification of the model might bring the model results closer to the monitored results in the mine;

- Although the stress values in the model do not fully compare with the monitoring data, the model can still be used to compare different mining scenarios in a rational way. One such example is to look at the critical stress conditions in critical mining steps in level 187;

- The stress results of the model give a clear impression that deeper mining levels pose more challenging conditions. It means that one may expect a more severe situation in level 155 and 123 than was experienced in level 187 during the critical mining steps; and

- It is recommended that the model can be further improved by several options or a combination of them, such as (a) adding random pillars in the central part of the mine; (b) simulating it with quartz-keratophyre having more stiff elastic properties, and (c) simulation using plastic material. 


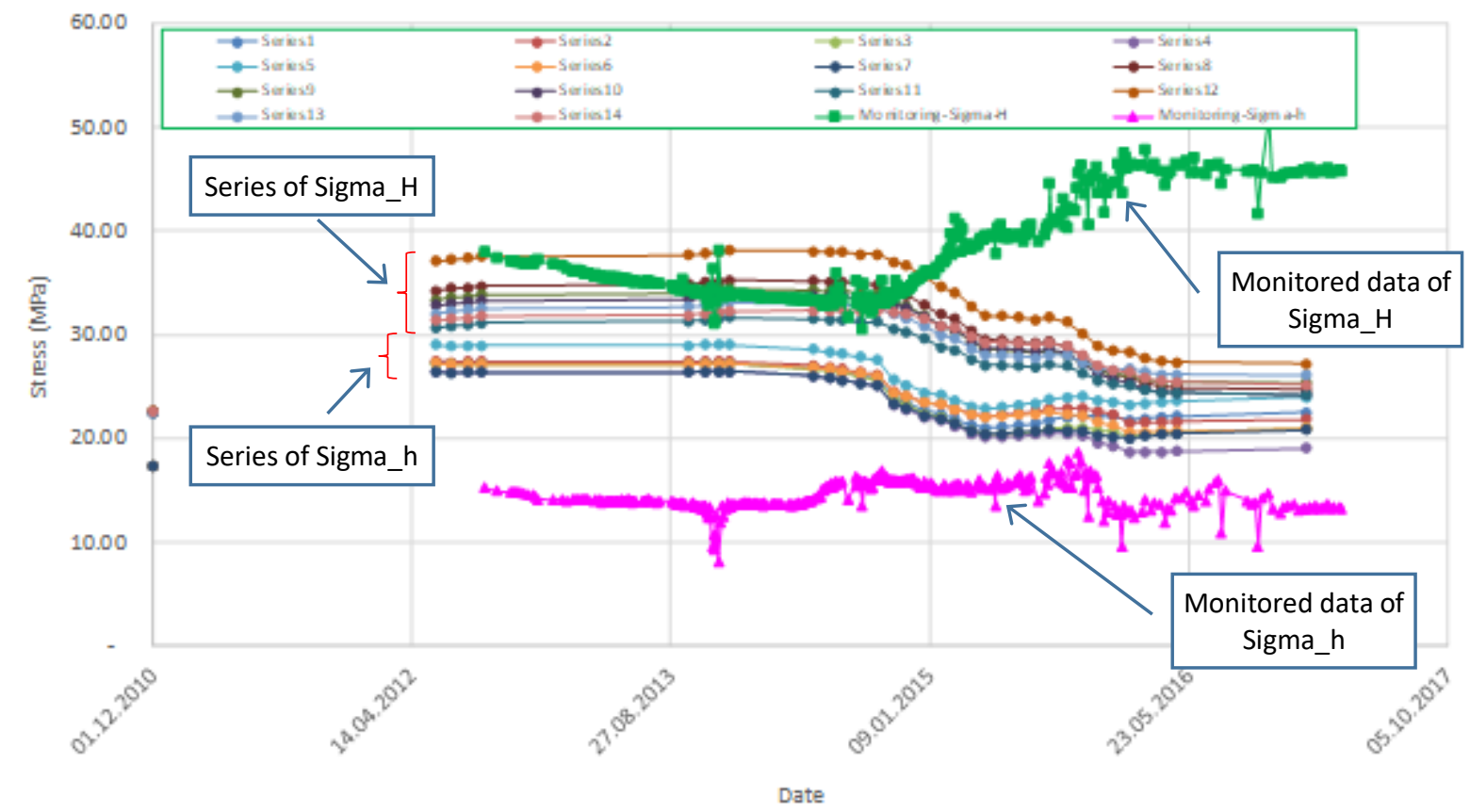

Figure 12. Typical comparison between numerical model results and monitoring data (each "Series" is corresponding for numerical model for each element within the $2 \mathrm{~m}$ radius spherical volume around the LTDM). The stress results from numerical model is projected and calculated in the same plane as the LTDM (horizontal plane) for a consistent comparison

\section{ACKNOWLEDGEMENTS}

The authors would like to express their thanks to Rana Gruber AS for permission to publish this paper. Many thanks also to Itasca Consultants Group (Jonny Sjöberg and colleagues) for help during construction of the geometry of the 3D model and related discussions.

\section{REFERENCES}

Rana Gruber AS (2019). History of the company. Website (access on 18/01/2019):

http://www.ranagruber.no/index.php?id=22

Sand, N.S. (2010). An alternative mining method at the Kvannevann Mine, northern Norway. In Caving 2010 Symposium, Australia: Perth.

Sand, N.S., and Trinh, Q.N. (2011). Rana Gruber rock mechanics challenges connection with the establishment of a new main level and the transition to new mining method. The 45th U.S. Rock Mechanics Symposium. Anthony Iannacchione, Gabriel Esterhuizen, and Azra Tutuncu (eds.). June 2011, San Francisco, USA.

SINTEF. (2011). Project report "Extensometer, 2-D stress measurement, and long-term doorstoppers in Rana Gruber". October 2011, Trondheim, Norway.

Trinh Q.N., Sand N. S., Myrvang A., (2010). Rock excavation and support for a crusher hall at Rana Gruber, Norway. The 44th U.S. Rock Mechanics Symposium and 5th U.S.-Canada Symposium. June 2010, Salt Lake City, USA.

Trinh Q.N., Sand N. S., (2011): Stability study for the footwall at Rana Gruber, Norway. The 45th U.S. Rock Mechanics Symposium. June 2011, San Francisco, USA. 
Trinh Q.N., Jonsson Kristina (2013). Design considerations for an underground room in a hard rock subjected to a high horizontal stress field at Rana Gruber, Norway. Tunnelling and Underground Space Technology, Volume 38, September 2013, Pages 205-212.

Trinh Q. N., Holmøy H. K., Larsen T., and Myrvang A., (2016). Continued rock stress and displacement measurements combined with numerical modeling as an active, realistic rock engineering tool. RS2016 Symposium, 7th International Symposium on In-Situ Rock Stress. May 10-12, 2016, Tampere, Finland.

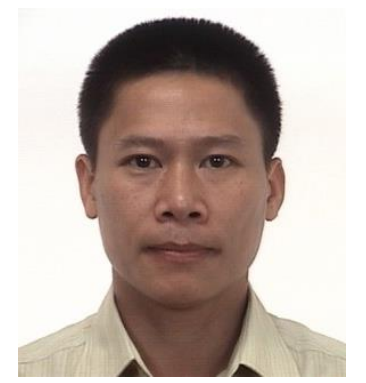

\section{Nghia Quoc Trinh}

Senior Researcher

SINTEF Building and Infrastructure

Got Ph.D. in rock engineering in 2006 at Norwegian University of Science and Technology. Having more than 10 years of experience working with different rock mechanics and rock engineering issues for tunnels and underground structures in infrastructure, hydropower, mining, and oil and gas. 